\title{
Nonanoic Acid-Coated Magnetite Nanoparticles for Separation and Preconcentration of Lead and Copper in Tobacco Samples prior to Flame Atomic Absorption Spectrometry Determination
}

\author{
Shouai Feng, ${ }^{a}$ Hong Liu,,${ }^{a}$ Jiangfeng Huang, ${ }^{a}$ Jingjing Wu, ${ }^{a}$ Kang Wei, ${ }^{a}$ Xiaolan Li, ${ }^{a}$ \\ Dongling Meng, ${ }^{a}$ Jiao Zhao $^{b}$ and Yaling Yang*,b \\ ${ }^{a}$ Technology Centre of China Tobacco Guangxi Industrial Co., LTD, \\ 530001 Nanning, Guangxi Province, China \\ ${ }^{b}$ Faculty of Life Science and Technology, Kunming University of Science and Technology, \\ 650500 Kunming, Yunnan Province, China
}

\begin{abstract}
A new method using nonanoic acid-coated magnetic $\mathrm{Fe}_{3} \mathrm{O}_{4}$ nanoparticles as adsorbent has been developed for the single-step extraction and preconcentration of lead and copper in tobacco samples. Transmission electron microscopy and X-ray diffraction spectrometry were used to characterize the adsorbent. The experimental parameters affecting extraction efficiency, including amount of nanoparticles, volume of chelating reagents, sample $\mathrm{pH}$, ultrasonic time and desorption conditions were investigated. The analytes desorbed from nanoparticles were determined by flame atomic absorption spectrometry. Under the optimum conditions, good linearity was obtained in the range of 2-400 $\mu \mathrm{g} \mathrm{L} \mathrm{L}^{-1}$ for copper and 5-800 $\mu \mathrm{g} \mathrm{L} \mathrm{L}^{-1}$ for lead $(\mathrm{r}>0.998, p<0.05)$. The limits of detection for copper and lead were 0.2 and $0.5 \mu \mathrm{g} \mathrm{L}^{-1}$, with enrichment factors of 45 and 52 , respectively. The method was successfully employed to tobacco sample analysis and got excellent recoveries between 89.2 and $100.7 \%$ with relative standard deviations $(n=6)$ of $4.5-5.9 \%$.
\end{abstract}

Keywords: magnetic solid phase extraction, lead, copper, tobacco samples, flame atomic absorption spectrometry

\section{Introduction}

Lead $(\mathrm{Pb})$ is one of the most common heavy metal contaminants in the environment, ${ }^{1}$ which ascribe to its widely application ${ }^{2}$ and $\mathrm{Pb}^{\mathrm{II}}$-induced oxidative stress contributes to the pathogenesis of $\mathrm{Pb}^{\text {II }}$ poisoning for disruption of the delicate prooxidant/antioxidant balance that exists within zooblasts. ${ }^{3}$ Copper $(\mathrm{Cu})$ occurs naturally in the earth's crust and small amounts of $\mathrm{Cu}$ are needed for healthy plant and animal growth. ${ }^{4}$ However, the release of $\mathrm{Cu}^{\mathrm{II}}$ from anthropogenic sources is of concern due to its potentially detrimental effects on both the environment and human health.

Tobacco is a rich source of metals as metals get preferentially enriched in the tobacco during plant growth or manufacturing process. ${ }^{5,6} \mathrm{As}$ two kinds of representative elements in tobacco, the determination of $\mathrm{Pb}^{\mathrm{II}}$ and $\mathrm{Cu}^{\mathrm{II}}$ in tobacco sample could afford some information of

*e-mail: yilyil8@163.com significant importance. Herewith, in order to help achieve meaningful regulation for tobacco products to decrease the side-effect delivered to users and those who are exposed to second hand smoke, quantitative determination of $\mathrm{Pb}^{\mathrm{II}}$ and $\mathrm{Cu}^{\mathrm{II}}$ at trace or even ultra-trace concentration levels has been required with great consideration..$^{7-10}$ However, an efficient preconcentration step is usually necessary prior to determination because of the low concentration of heavy metals and the complexity of the tobacco samples. In recent years, sample preparation has witnessed transformation with the main efforts focused on acceleration, simplification, miniaturization and automation of the operations involved. ${ }^{11}$

Recently, magnetic solid-phase extraction (MSPE) has been intensively used for environmental analysis at trace levels. ${ }^{12-15}$ In this technique, magnetic nanoparticles (MNPs), as adsorbent, were served without any packing of cartridges. They were just added into a sample solution containing target analytes. After adsorption, MNPs can be easily removed from sample solution using a magnet 
placed outside of the extraction container. The main advantages of MSPE include low price, rapidity, simplicity and reusability. ${ }^{13}$ However, naked MNPs tend to form agglomerates, as well as, they are chemically active and oxidize in air, resulting in loss of magnetism. ${ }^{16}$

In this work, $\mathrm{Fe}_{3} \mathrm{O}_{4} \mathrm{NPs}$ were synthesized via a simple chemical co-precipitation method and modified by nonanoic acid (designated $\mathrm{Fe}_{3} \mathrm{O}_{4} @ \mathrm{NA}$ ) which was used as effective magnetic adsorbent. Ammonium pyrrolidine dithiocarbamate (APDC) was used as the chelating agent. By virtue of possessing nitrogen and sulfur donor atoms and a conjugated $\pi$ system, $\mathrm{Pb}^{\mathrm{II}}$ and $\mathrm{Cu}^{\mathrm{II}}$ could form stable complexes with APDC. The hydrophobic groups of metal complexes were critical in attaining high extraction recovery in MSPE because adsorption of metal complexes to $\mathrm{Fe}_{3} \mathrm{O}_{4} @ \mathrm{NA}$ may be produced by the electrostatic and hydrophobic interaction. In addition, the metal complexes can be well adsorbed on the surface of nanocomposite, in which $\mathrm{Fe}_{3} \mathrm{O}_{4} @ \mathrm{NA}$ MNPs provide hydrophobic groups and $\pi-\pi$ interaction to promote adsorption. In the presence of APDC, both $\mathrm{Pb}^{\mathrm{II}}$ and $\mathrm{Cu}^{\mathrm{II}}$ were effectively adsorbed on the surface of $\mathrm{Fe}_{3} \mathrm{O}_{4} @ \mathrm{NA}$ nanoparticles by forming hydrophobic metal complexes, which was applied for preconcentration of $\mathrm{Pb}^{\mathrm{II}}$ and $\mathrm{Cu}^{\mathrm{II}}$.

The functionalized magnetic nanoparticles showed good selectivity for extraction and preconcentration of $\mathrm{Pb}^{\mathrm{II}}$, and $\mathrm{Cu}^{\mathrm{II}}$ in tobacco samples. The advantages of this separation technology are that $\mathrm{Pb}^{\mathrm{II}}$ and $\mathrm{Cu}^{\mathrm{II}}$ together with the magnetic particles can be eliminated from the sample solution by a simple magnetic field. After magnetic separation, the harmful components can be easily removed from the magnetite particles, and the recovered magnetic particles can be reused. The nanoparticles were characterized by transmission electron microscope (TEM) and X-ray diffraction (XRD). The parameters affecting the extraction recoveries of magnetic solid-phase extraction, which include amount of sorbent, sample $\mathrm{pH}$, volume of APDC, ultrasonication time, interference, sample volume and elution conditions, have been optimized.

\section{Experimental}

\section{Instrumentation}

A closed-vessel microwave furnace (WX-4000, China) was used for sample decomposition. An ultrasonic bath (Shanghai, China) was used to disperse the nanoparticles in solutions. A flame atomic absorption spectrometer (F AAS, AA-6300C, Shimadzu, Japan) with ethyne flame and hallow cathode lamps was used for the determination of $\mathrm{Pb}$ and $\mathrm{Cu}$. The operating conditions are given in Table 1 .
A scanning electron microscopy (SEM) scanning system VEGA3 SBH (Tescan, Czech Republic) with a tungsten electron gun was used to provide electron beam irradiation for characterization of $\mathrm{Fe}_{3} \mathrm{O}_{4}$ NPs. A transmission electron microscope scanning system of Tecnai G2 TF30 S-Twin (FEI, Holland) was used for characterization of $\mathrm{Fe}_{3} \mathrm{O}_{4} @ \mathrm{NA}$ nanoparticles. The powder X-ray diffraction patterns of nanoparticles were measured by a Rigaku D/max 2200 powder diffraction meter (Rigaku, Japan). The $\mathrm{pH}$ values were measured by a pH-meter Model pHS-3S (Shanghai, China). Surface area measurements of MNPs were performed by Brunauer-Emmett-Teller (BET) method at liquid nitrogen temperatures using conventional gas adsorption apparatus (F-Sorb 2400, China).

Table 1. Instrumental parameters for F AAS determination of the $\mathrm{Pb}$ and $\mathrm{Cu}$

\begin{tabular}{lcc}
\hline Condition & $\mathrm{Pb}$ & $\mathrm{Cu}$ \\
\hline Analytical wavelength / nm & 283.3 & 324.7 \\
Lamp current / mA & 10 & 10 \\
Spectral band pass / nm & 0.7 & 0.7 \\
\hline
\end{tabular}

Reagents, standards and samples

$\mathrm{Pb}^{\mathrm{II}}$ and $\mathrm{Cu}^{\mathrm{II}}$ working standard solutions were prepared daily by stepwise dilution from standard stock solution $\left(1000 \mathrm{mg} \mathrm{L}^{-1}\right)$ in $0.1 \% \mathrm{HNO}_{3}$. Ammonium pyrolysine dithiocarbamate (APDC), $\mathrm{FeCl}_{3} \cdot 6 \mathrm{H}_{2} \mathrm{O}$, $\left(\mathrm{NH}_{4}\right)_{2} \mathrm{Fe}\left(\mathrm{SO}_{4}\right)_{2} \cdot 6 \mathrm{H}_{2} \mathrm{O}$, methanol and $\mathrm{HNO}_{3}$, nonanoic acid were analytical grades and purchased from Aladdin company (Shanghai, China). The certified reference sample (GBW(E)080039) from the Chinese reference materials was used to evaluate the method accuracy.

\section{Synthesis of nonanoic acid-coated magnetic nanoparticles}

Nonanoic acid-coated magnetic nanoparticles $\left(\mathrm{Fe}_{3} \mathrm{O}_{4} @ \mathrm{NA}\right)$ were synthesized by a one-step co-precipitation method ${ }^{17}$ with some modification. The procedure was as follows: $1.41 \mathrm{~g} \mathrm{FeCl}_{3} \cdot 6 \mathrm{H}_{2} \mathrm{O}$ and $2.25 \mathrm{~g}$ $\left(\mathrm{NH}_{4}\right)_{2} \mathrm{Fe}\left(\mathrm{SO}_{4}\right)_{2} \cdot 6 \mathrm{H}_{2} \mathrm{O}$ were dissolved in $40 \mathrm{~mL}$ of deionized water under vigorous stirring and nitrogen gas protection. As the solution was heated to $80{ }^{\circ} \mathrm{C}$ in a water bath, $5 \mathrm{~mL}$ of $25 \% \mathrm{NH}_{4} \mathrm{OH}$ solution was added under stirring. After $5 \mathrm{~min}, 1 \mathrm{~mL}$ nonanoic acid was slowly added to the obtained suspension. The resulting suspension was kept for $30 \mathrm{~min}$ at $85^{\circ} \mathrm{C}$ with constant stirring under nitrogen atmosphere. Then, the suspension was allowed to cool to room temperature. The precipitates was isolated from the mixture with the help of a permanent magnet and washed three times with deionized water. The obtained 
$\mathrm{Fe}_{3} \mathrm{O}_{4} @$ NA MNPs were diluted to $10 \mathrm{~mL}$ with deionized water and stored in a freezer $\left(4{ }^{\circ} \mathrm{C}\right)$ for further use, the concentration of $\mathrm{Fe}_{3} \mathrm{O}_{4} @ \mathrm{NA}$ suspension was estimated to be about $20 \mathrm{mg} \mathrm{mL}^{-1}$ and the mass of $\mathrm{Fe}_{3} \mathrm{O}_{4} @ \mathrm{NA}$ nanoparticles in the suspension was estimated to be about $200 \mathrm{mg}$.

\section{Magnetic solid phase extraction procedures}

A magnetic solid phase extraction experiment required the following steps: $50 \mathrm{~mL}$ of aqueous solution containing $100 \mu \mathrm{g} \mathrm{L}^{-1}$ of $\mathrm{Cu}, 100 \mu \mathrm{g} \mathrm{L}^{-1}$ of $\mathrm{Pb}$ and $100 \mu \mathrm{L}$ of APDC was adjusted to pH 7 with $0.5 \mathrm{M}$ of $\mathrm{NaOH}$. $200 \mu \mathrm{L}$ of $\mathrm{Fe}_{3} \mathrm{O}_{4} @ \mathrm{NA}$ MNPs suspension were added and the mixture was ultrasonicated for $10 \mathrm{~min}$. Then, the magnetic nanoparticles with adsorbed metals ions were separated from the suspension by an $\mathrm{Nd}-\mathrm{Fe}-\mathrm{B}$ permanent magnet and the supernatant was decanted directly, the residual MNPs were eluted by $1 \mathrm{~mL}$ methanol-nitric acid and ultrasonicated for $1 \mathrm{~min}$ for desorption of adsorbed Pb-APDC and $\mathrm{Cu}-\mathrm{APDC}$. Finally, the magnet was used again to collect the nanoparticles, and the eluent was transferred into a test tube for subsequent F AAS analysis. A blank sample was also treated in the same way as the sample but without addition of the analytes. The experimental steps were illustrated in Figure 1.

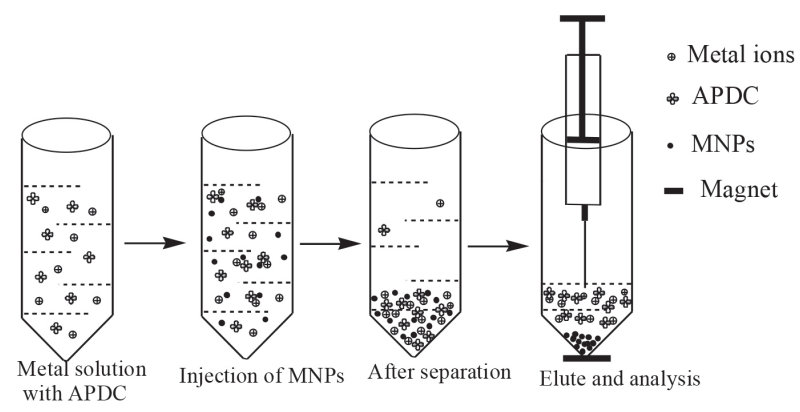

Figure 1. Schematic diagram of magnetic solid-phase extraction procedure.

\section{Application of real samples}

The flue-cured tobacco samples were supplied by China Tobacco Guangxi Industrial Corporation Ltd (China).

Three real tobacco samples $(200 \mathrm{mg})$ were weighed in PTFE vessels and about $4 \mathrm{~mL}$ of $\mathrm{HNO}_{3}$ was added to each vessel and kept for $10 \mathrm{~min}$ at room temperature. Then, the vessels were sealed tightly and then positioned in the carousel of the microwave oven (WX 4000). The system was operated as indicated in Table 2. After completion of the digestion, the digestion vessels were removed from microwave oven when the temperature dropped to $70^{\circ} \mathrm{C}$. On cooling at room temperature, digestion solutions were transferred into a $50 \mathrm{~mL}$ centrifuge tubes and diluted to $50 \mathrm{~mL}$ with deionized water. A blank sample was also conducted under the same procedure, but without addition of the tobacco samples. Then the procedure of MSPE was performed.

\section{Results and Discussion}

\section{Characteristics of adsorbent}

TEM images of the $\mathrm{Fe}_{3} \mathrm{O}_{4} @ \mathrm{NA}$ nanoparticles (Figure 2) revealed the $\mathrm{Fe}_{3} \mathrm{O}_{4} @ \mathrm{NA}$ nanoparticles to be well defined sphere-shaped structures and the smallest percentage (80\%) was found for $10-30 \mathrm{~nm}$ particles. The TEM images also showed that the edge morphology of $\mathrm{Fe}_{3} \mathrm{O}_{4} @$ NA NPs became blurred because the particles' surface was encapsulated with nonanoic acid and the prepared $\mathrm{Fe}_{3} \mathrm{O}_{4} @ \mathrm{NA}$ NPs were stabilized against agglomeration by monolayer of nonanoic acid. The crystalline structures of $\mathrm{Fe}_{3} \mathrm{O}_{4}$ and $\mathrm{Fe}_{3} \mathrm{O}_{4} @ \mathrm{NA}$ were identified with XRD. For $\mathrm{Fe}_{3} \mathrm{O}_{4} \mathrm{NPs}$ (Figure 3a), diffraction peaks with $2 \theta$ of $30.2,35.5,43.1,53.9,57.3$, and $62.9^{\circ}$ were observed, corresponding to the diffraction plane of 220 , 311, 400, 422, 511, and 440, respectively. Furthermore, the same sets of characteristic peaks were also observed for $\mathrm{Fe}_{3} \mathrm{O}_{4} @ \mathrm{NA}$ (Figure 3b), indicating the stability of the crystalline phase of $\mathrm{Fe}_{3} \mathrm{O}_{4}$ NPs after coated with nonanoic acid. ${ }^{18-20}$ BET results suggested that $\mathrm{Fe}_{3} \mathrm{O}_{4} @ \mathrm{NA}$ NPs has higher surface area of $189.1 \mathrm{~m}^{2} \mathrm{~g}^{-1}$ than $\mathrm{Fe}_{3} \mathrm{O}_{4}$ NPs of $120.5 \mathrm{~m}^{2} \mathrm{~g}^{-1}$. Since the available active sites for $\mathrm{Fe}_{3} \mathrm{O}_{4} @ \mathrm{NA}$ are mostly present outside of the surface, higher surface area means more adsorption sites for $\mathrm{Pb}$ and $\mathrm{Cu}$.

\section{Optimization of MSPE parameters}

In order to select the optimum MSPE conditions for the extraction of $\mathrm{Pb}$ and $\mathrm{Cu}, 50 \mathrm{~mL}$ deionized water

Table 2. Program of microwave digestion

\begin{tabular}{lcccc}
\hline Step & Power $/ \mathrm{W}$ & Heating up time $/ \mathrm{min}$ & Temperature $/{ }^{\circ} \mathrm{C}$ & Holding time $/ \mathrm{min}$ \\
\hline 1 & 800 & 5 & 100 & 4 \\
2 & 800 & 5 & 150 & 4 \\
3 & 800 & 5 & 180 & 10 \\
\hline
\end{tabular}



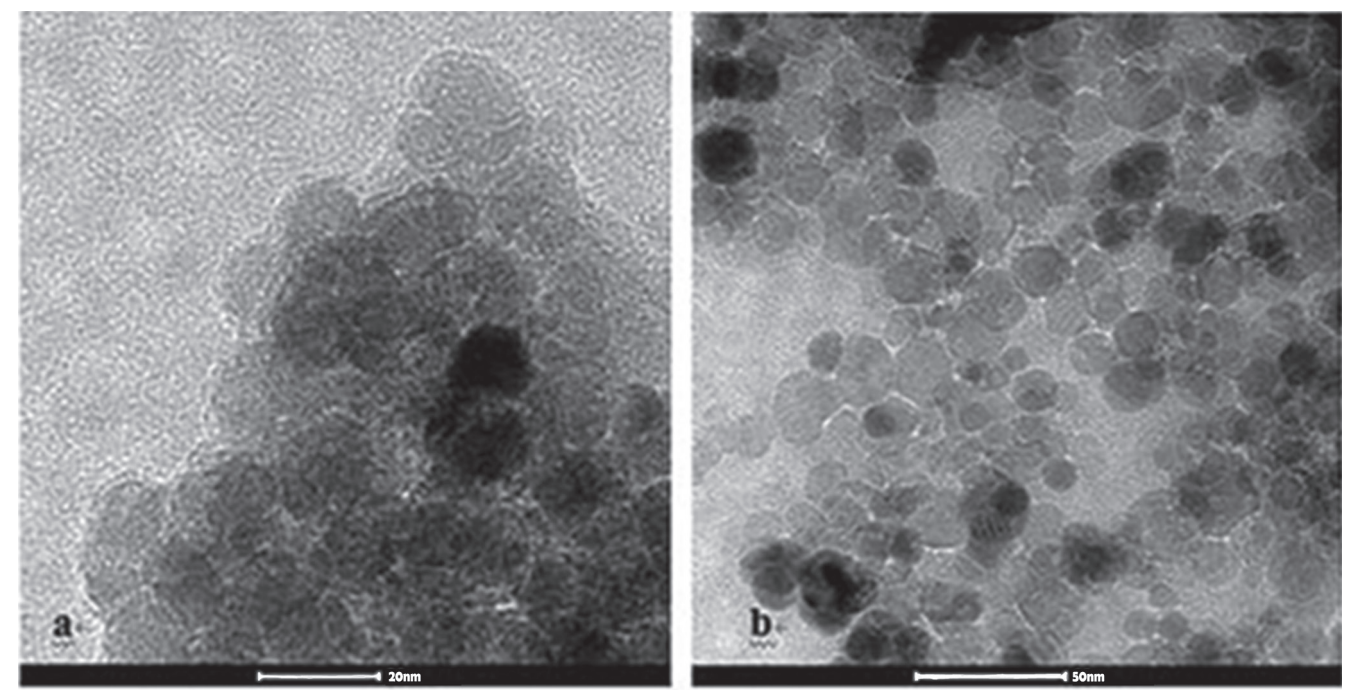

Figure 2. Transmission electron microscope images of nonanoic acid-coated magnetic $\mathrm{Fe}_{3} \mathrm{O}_{4}$ nanoparticles in different magnifications: (a)100,000x; (b) $40,000 x$.
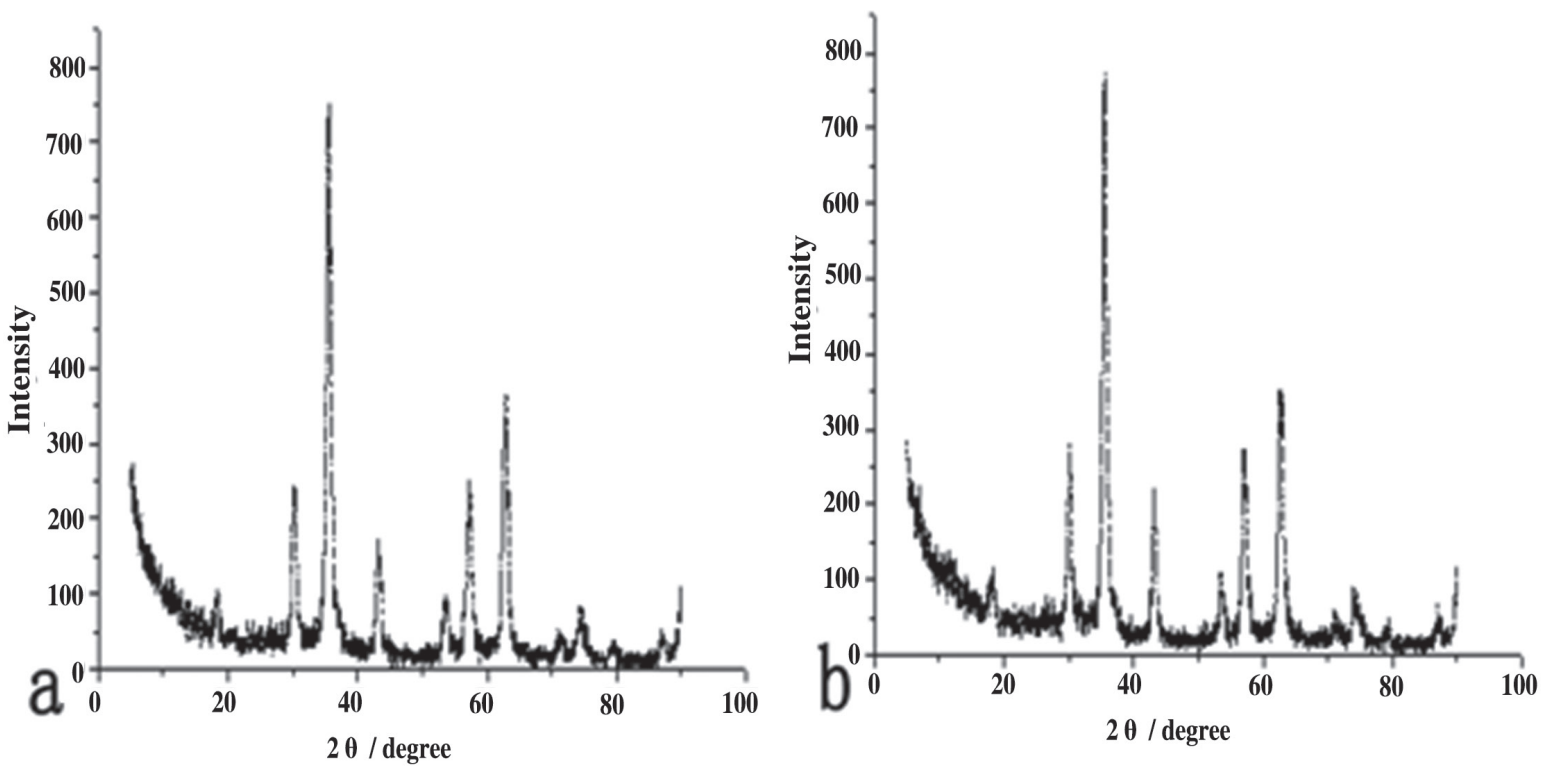

Figure 3. X-ray diffraction patterns of (a) $\mathrm{Fe}_{3} \mathrm{O}_{4}$ nanoparticles and (b) nonanoic acid-coated magnetic $\mathrm{Fe}_{3} \mathrm{O}_{4}$ nanoparticles.

spiked with $100 \mu \mathrm{g} \mathrm{L}{ }^{-1}$ of $\mathrm{Pb}$ and $\mathrm{Cu}$ was used to study the extraction performance of the MSPE, $\mathrm{Fe}_{3} \mathrm{O}_{4} @ \mathrm{NA}$ MNPs were used as adsorbents. All the experiments were performed in triplicate and the means of the results were used for optimization.

\section{Sorbent type}

In this context, extraction abilities of $\mathrm{Fe}_{3} \mathrm{O}_{4}$ NPs and $\mathrm{Fe}_{3} \mathrm{O}_{4} @ \mathrm{NA}$ NPs were investigated as the sorbent type was an important parameter affecting the extraction efficiency. Compared to bare $\mathrm{Fe}_{3} \mathrm{O}_{4} \mathrm{NPs}$, the carbon chain of nonanoic acid modified $\mathrm{Fe}_{3} \mathrm{O}_{4} @ \mathrm{NA}$ NPs can interact with the complexes (Pb-APDC, Cu-APDC) through hydrophobic interaction and having better adsorption capacity.

\section{Effect of $\mathrm{pH}$}

In the adsorption of metal ions, the $\mathrm{pH}$ plays a distinctive role on metal-chelate formation and adsorption efficiency. The influence of $\mathrm{pH}$ on the adsorption behavior of $\mathrm{Pb}$ and $\mathrm{Cu}$ in presence and absence of APDC was investigated over the $\mathrm{pH}$ range of 3-13. As can be seen in Figure 4, in the absence of APDC, the recoveries for $\mathrm{Pb}$ and $\mathrm{Cu}$ were only about $30-60 \%$ in the tested $\mathrm{pH}$ range. However, in the presence of APDC, $\mathrm{Pb}$ and $\mathrm{Cu}$ were efficiently adsorbed on the nanoparticles at $\mathrm{pH} 7$ and good recoveries were obtained by forming metal complexes. The hydrophobicity of Pb-APDC and Cu-APDC are much higher than $\mathrm{Pb}$ and $\mathrm{Cu}$, so when APDC exists, $\mathrm{Pb} / \mathrm{Cu}-\mathrm{APDC}$ could be efficiently adsorbed by the hydrophobic nonanoic acid-coated $\mathrm{Fe}_{3} \mathrm{O}_{4}$ NPs. In addition, the magnetic 
adsorbents exhibited low adsorption of $\mathrm{Pb}$ and $\mathrm{Cu}$ when the $\mathrm{pH}$ value was below 7, that because partial Fe were dissolved from $\mathrm{Fe}_{3} \mathrm{O}_{4} @ \mathrm{NA}$ in the acidic solution, and the adsorb ability of MNPs decreased. At $\mathrm{pH}$ values exceeding 7, the adsorption efficiency would be decreased due to the formation of metal hydroxide precipitates. ${ }^{21}$ Overall consideration, a sample $\mathrm{pH}$ about 7 was selected to guarantee fully chelation and excellent adsorption for subsequent work.

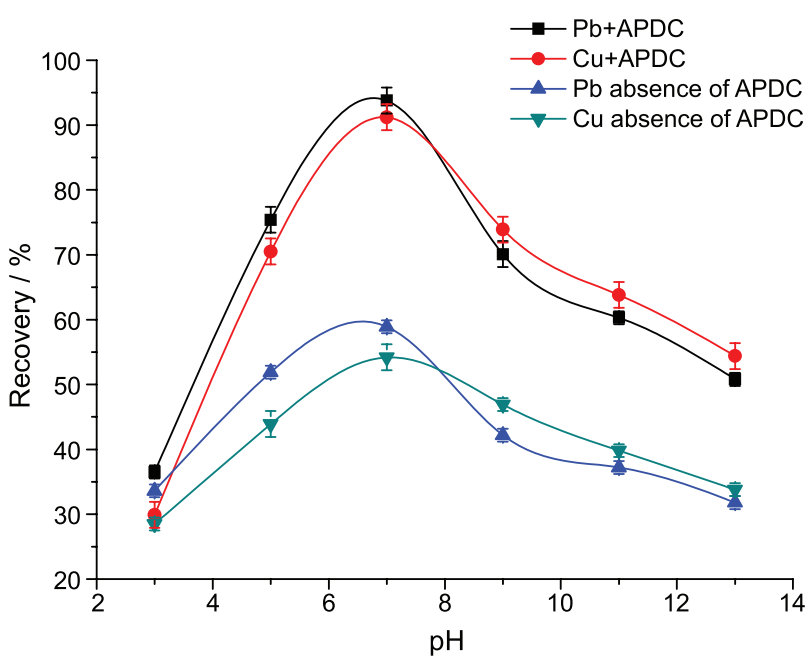

Figure 4. Effect of the solution $\mathrm{pH}$ on the recoveries. Concentration of each analyte: $100 \mu \mathrm{g} \mathrm{L}{ }^{-1}$; volume of chelating agent: $100 \mu \mathrm{L}$; amount of nanoparticles: $4 \mathrm{mg}$; sonication time: $10 \mathrm{~min}$; sample volume: $50 \mathrm{~mL}$; elution solvent: $1 \mathrm{~mL} 1 \%$ nitric acid-methanol.

\section{Effect of volume of chelating agent}

As the principle reagent in this work, APDC was selected as chelating agent to form $\mathrm{Cu} / \mathrm{Pb}$-chelate complex. The composition of the produced complex is critical in attaining higher extraction percentages. The effect of the amount of APDC on the extraction recoveries of $\mathrm{Cu}$ and $\mathrm{Pb}$ was examined by adding variable amounts, from 0 to $250 \mu \mathrm{L}$, of a solution of $100 \mu \mathrm{g} \mathrm{mL} \mathrm{m}^{-1}$. As illustrated in Figure 5, it was found that the extraction efficiency of each target analyte was very low when no APDC was added, the recovery increased with the increasing of chelating reagent volume in certain ranges and at higher volume of APDC the recovery kept stable. Thus, $100 \mu \mathrm{L}$ of APDC was chosen for further experiments.

\section{Effect of the sorbent amount}

To inspect the effect of sorbent quantity on the extraction efficiency, different volumes of $\mathrm{Fe}_{3} \mathrm{O}_{4} @ \mathrm{NA}$ suspension (20 mg mL $\mathrm{m}^{-1}$ ) within the range of $50-300 \mu \mathrm{L}$ were added to the solution. As shown in Figure 6, the best extraction efficiency of metal ions could be obtained using $200 \mu \mathrm{L}$

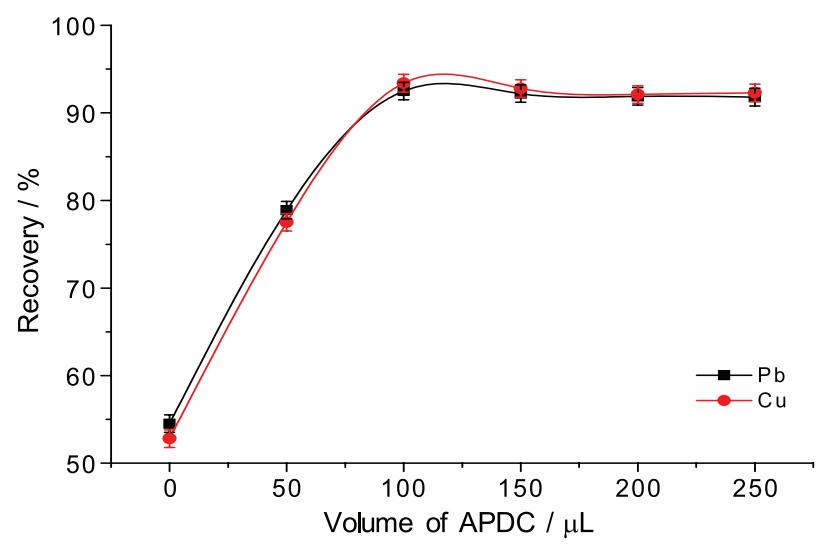

Figure 5. Effect of the volume of chelating agent on the recoveries. Concentration of each analyte: $100 \mu \mathrm{g} \mathrm{L}{ }^{-1} ; \mathrm{pH}: 7$; amount of nanoparticles: $4 \mathrm{mg}$; sonication time: $10 \mathrm{~min}$; sample volume: $50 \mathrm{~mL}$; elution solvent: $1 \mathrm{~mL} 1 \%$ nitric acid-methanol.

of sorbent $(4 \mathrm{mg})$. Compared to the ordinary sorbents, magnetic nano-sized sorbents have higher surface areas and strong magnetization, therefore, satisfactory results can be obtained by lower amounts of MNPs. Also, due to the shorter diffusion route for MNPs and the magnetically separation of the MNPs from the turbid sample solutions, the extraction of $\mathrm{Cu}$ and $\mathrm{Pb}$ can be achieved in a shorter time and by simple process.

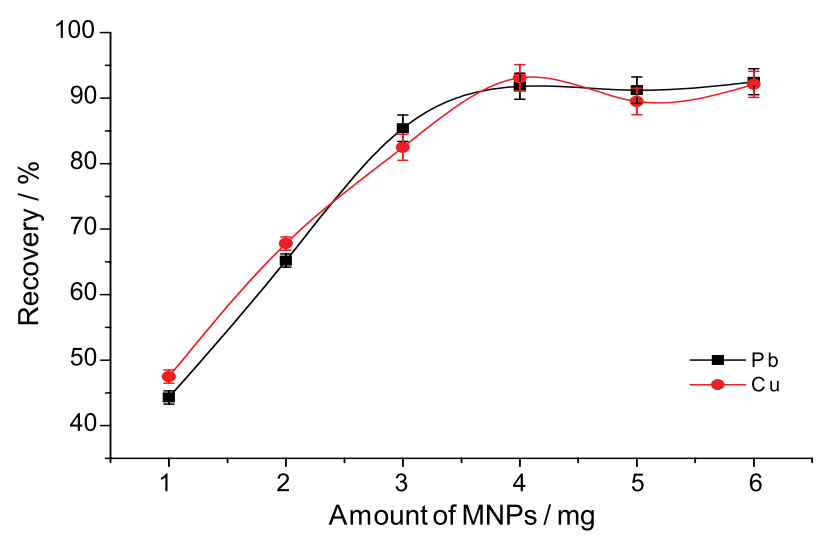

Figure 6. Effect of amount of nanoparticles on the recoveries. Concentration of each analyte: $100 \mu \mathrm{g} \mathrm{L}-1$; $\mathrm{pH}$ : 7; volume of chelating agent: $100 \mu \mathrm{L}$; sonication time: $10 \mathrm{~min}$; sample volume: $50 \mathrm{~mL}$; elution solvent: $1 \mathrm{~mL} 1 \%$ nitric acid-methanol.

\section{Effect of ultrasonication time}

In the process of adsorption, the ultrasonication time is one of the prime factors influencing the target analyte extraction. The extraction efficiency of the two metal elements increased with increasing sonication time and remained constant above $10 \mathrm{~min}$. The best recoveries can be achieved by choosing ultrasonic frequency at $25 \mathrm{~Hz}$, a sonication time of $10 \mathrm{~min}$. The results (Figure 7) clearly indicate that sonication time of $10 \mathrm{~min}$ was found to be 
sufficient for the quantitative adsorption of $\mathrm{Cu}$ and $\mathrm{Pb}$ from tobacco samples.

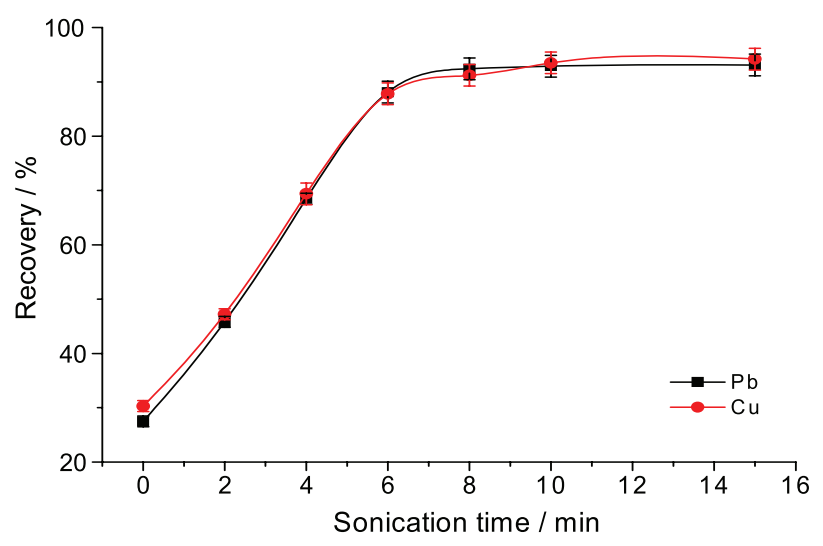

Figure 7. Effect of sonication time on the recoveries. Concentration of each analyte: $100 \mu \mathrm{g} \mathrm{L}^{-1}$; $\mathrm{pH}$ : 7; volume of chelating agent: $100 \mu \mathrm{L}$; amount of nanoparticles: $4 \mathrm{mg}$; sample volume: $50 \mathrm{~mL}$; elution solvent: $1 \mathrm{~mL} 1 \%$ nitric acid-methanol.

\section{Effect of the volume of sample}

Magnetic solid phase extraction technology avoids many time-consuming steps such as column passing sample loading or filtration and shows a great potential for preconcentration of large volume samples. The volume of test solution was investigated by varying the parameter in the range of $20-60 \mathrm{~mL}$ and the result was shown as Figure 8. With the volume of test solution increased, the recoveries showed a declined tendency. Therefore, $50 \mathrm{~mL}$ was selected as optimum value for further experiments.

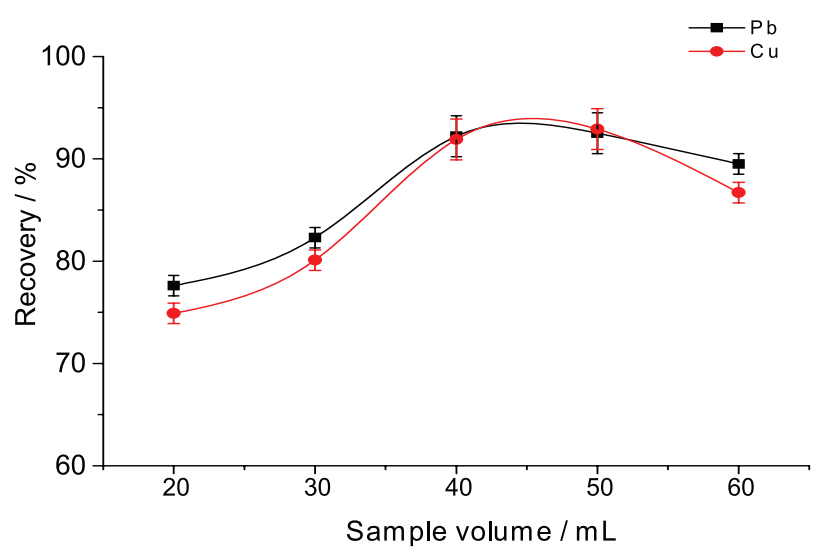

Figure 8. Effect of sample volume on the recoveries. Concentration of each analyte: $100 \mu \mathrm{g} \mathrm{L}^{-1}$; $\mathrm{pH}$ : 7; volume of chelating agent: $100 \mu \mathrm{L}$; amount of nanoparticles: $4 \mathrm{mg}$; sonication time: $10 \mathrm{~min}$; elution solvent: $1 \mathrm{~mL} 1 \%$ nitric acid-methanol.

\section{Effect of type and volume of eluent solvent}

In order to desorb the metal ions from MNPs surfaces and obtain highest recoveries, a series of eluting solutions, including methanol, acetonitrile, acidified methanol and acidified acetonitrile, which were used as eluting solution, were investigated. The results indicated that the elution by methanol and acetonitrile provided recoveries $>80.5 \%$, and the best recoveries ( $92.3 \%$ for $\mathrm{Cu}$ and $93.8 \%$ for $\mathrm{Pb}$ ) were obtained using $1 \mathrm{~mL}$ of $\mathrm{HNO}_{3}$-methanol $(1: 99, \mathrm{v} / \mathrm{v})$ as eluting solution.

Reusability of adsorbent

In order to investigate the recycling of the adsorbent, the adsorbent were rinsed sequentially with methanol, acetonitrile, and deionized water to purify the adsorbent before application in the next time. The results showed that the recoveries of analyte ions were over $85.2 \%$ with three reuses. The results of this study indicate that the adsorbent is reusable without a considerable loss in its adsorption efficiency for $\mathrm{Cu}$ and $\mathrm{Pb}$ during extraction procedure.

\section{Selectivity}

To some degree, $\mathrm{Fe}_{3} \mathrm{O}_{4} @ \mathrm{NA}$ magnetic nanoparticles also have some adsorption for other heavy metals (such as $\mathrm{Cd}, \mathrm{Mn}, \mathrm{Ni}, \mathrm{Mg}$ and $\mathrm{Zn}$ ) under the optimal experimental conditions. Thus, the recoveries of the same concentration of each ion were compared to investigate the selective adsorption of $\mathrm{Fe}_{3} \mathrm{O}_{4} @ \mathrm{NA}$ MNPs. As shown in Table 3, the target metals $(\mathrm{Cu}$ and $\mathrm{Pb})$ showed higher recoveries (>90.1\%). This indicates that the selectivity adsorption of $\mathrm{Cu}$ and $\mathrm{Pb}$ to $\mathrm{Fe}_{3} \mathrm{O}_{4} @ \mathrm{NA}$ MNPs is satisfactory.

Table 3. Selectivity of different heavy metals

\begin{tabular}{lccc}
\hline Analyte & $\begin{array}{c}\text { Concentration / } \\
\left(\mu \mathrm{g} \mathrm{L}^{-1}\right)\end{array}$ & Recovery / \% & $\operatorname{RSD}(\mathrm{n}=6) / \%$ \\
\hline $\mathrm{Cu}^{2+}$ & 100 & 90.1 & 2.8 \\
$\mathrm{~Pb}^{2+}$ & 100 & 92.6 & 4.1 \\
$\mathrm{Cd}^{2+}$ & 100 & 56.6 & 3.1 \\
$\mathrm{Mn}^{2+}$ & 100 & 45.1 & 4.5 \\
$\mathrm{Ni}^{2+}$ & 100 & 62.1 & 4.3 \\
$\mathrm{Mg}^{2+}$ & 100 & 34.5 & 2.1 \\
$\mathrm{Zn}^{2+}$ & 100 & 81.9 & 3.6 \\
\hline
\end{tabular}

Interference study

Generally, the coexisting substances in the solution may compete with target analyte complex for the active sites of adsorbent. Besides, the coexisting ions also may compete with the analyte ion for APDC in the present study. The effects of coexisting ions on the determination of $\mathrm{Pb}$ and $\mathrm{Cu}$ were investigated under the optimized conditions. The 
results showed that with different ratios of interfering ions to the analytes, the recoveries of $\mathrm{Pb}$ and $\mathrm{Cu}$ were still above $89.2 \%$. From these experimental results in Table 4, it can be concluded that large numbers of ions have no considerable effect on the determination of $\mathrm{Pb}$ and $\mathrm{Cu}$, and the developed method has a good tolerance to the interference.

Table 4. Tolerance ratios of diverse ions on the determination of $100 \mu \mathrm{g} \mathrm{L}^{-1}$ of $\mathrm{Pb}$ and $100 \mu \mathrm{g} \mathrm{L}^{-1}$ of $\mathrm{Cu}(\mathrm{n}=6)$

\begin{tabular}{lccc}
\hline \multirow{2}{*}{ Foreign ion } & \multirow{2}{*}{$\begin{array}{c}\text { Ratio of interfering ions } \\
\text { to the analytes }\end{array}$} & \multicolumn{2}{c}{ Recovery / \% } \\
\cline { 3 - 4 } $\mathrm{Na}^{+}, \mathrm{K}^{+}$ & 5000 & 90.1 & $\mathrm{Cu}$ \\
$\mathrm{Zn}^{2+}, \mathrm{Ba}^{2+}, \mathrm{Fe}^{3+}$ & 2000 & 91.7 & 91.7 \\
$\mathrm{Ca}^{2+}, \mathrm{Mg}^{2+}$ & 1500 & 91.9 & 90.8 \\
$\mathrm{Mn}^{2+}, \mathrm{Cd}^{2+}$ & 800 & 94.6 & 89.2 \\
$\mathrm{Co}^{2+}, \mathrm{Ni}^{2+}$ & 400 & 93.8 & 96.7 \\
\hline
\end{tabular}

\section{Analytical figures of merit}

Analytical figures of merit of the proposed method was obtained and summarized in Table 5. The enrichment factors (EFs) were the ratios of the analytes concentration in eluent solvent to the initial concentration in the tobacco extracting solution. Calibration curve in F AAS was achieved by means of a concentration gradient using single standard solution after magnetic solid-phase extraction (MSPE). Under the optimal conditions of MSPE and FAAS, calibration curves were constructed for the analytes. The calibration curve for $\mathrm{Pb}$ was $\mathrm{A}=0.005063 \mathrm{C}-0.0006$, and for $\mathrm{Cu}$ was $\mathrm{A}=0.005286 \mathrm{C}+0.0027$, where $\mathrm{A}$ is the absorbance and $\mathrm{C}$ is the concentration. The limits of determination (LODs, defined as $3 \sigma_{b} / \mathrm{m}$, where, $\sigma_{b}$ is the standard deviation of absorbance values of blank solution, $\mathrm{m}$ is the slope of calibration curve) were 0.5 and $0.2 \mu \mathrm{g} \mathrm{L}^{-1}$ for $\mathrm{Pb}$ and $\mathrm{Cu}$, respectively. The limits of quantitation (LOQs, $10 \sigma_{\mathrm{b}} / \mathrm{m}$ ) were 1.7 and $0.7 \mu \mathrm{g} \mathrm{L}^{-1}$ for $\mathrm{Pb}$ and $\mathrm{Cu}$, respectively. Data obtained were fitted by linear regression analysis and the coefficients of regression and regression analysis of variance were calculated by chemical data (SAS 9.3). The results of one-way analysis of variance confirmed that good linearity $(r>0.998)$ was obtained in the range of 2-400 $\mu \mathrm{g} \mathrm{L}^{-1}$ for $\mathrm{Cu}$ and 5-800 $\mu \mathrm{g} \mathrm{L}^{-1}$ for $\mathrm{Pb}(p<0.05)$. The precision of analytical method expressed as RSD were calculated as 5.9 and $4.5 \%$ of $\mathrm{Pb}$ and $\mathrm{Cu}$, respectively.

\section{Samples analysis}

At present, China has not formulated the limit standard for heavy metals in tobacco. In this study, we refer to the limits of heavy metals in food by Chinese Standard of 50-500 $\mu \mathrm{g} \mathrm{kg}^{-1}$, and the spiked concentration of metals were 50, 100 and $200 \mu \mathrm{g} \mathrm{kg}^{-1}$. Three tobacco samples were detected by this method, the analytical results are given in Table 6 and the recoveries for the samples spiked with different concentrations of metal ions were in the acceptable range of $89.2-100.7 \%$. Besides the real samples, the certified sample (GBW(E)080039) was analyzed to validate the accuracy of the proposed method. Table 7 represents the certified content and obtained values of metal ions for the certified samples. Results indicate that there are good agreements between certified and obtained values of the elements and it can be concluded that the proposed method is accurate and free of systematic errors.

\section{Conclusions}

In this study, the fast and simple magnetic solid phase extraction procedure followed by F AAS was proposed for the determination of $\mathrm{Pb}$ and $\mathrm{Cu}$ in tobacco samples. The synthesis process of nonanoic acid-coated magnetite nanoparticles was extremely simple and time saving. The magnetic solid phase extraction procedure eliminates the need for lengthy and laborious procedures for sample preparation which is advantageous for high sample throughput, because the MNPs have generally high surface area and fast magnetic separation. Besides the considerably high preconcentration ability for $\mathrm{Pb}$ and $\mathrm{Cu}$, the proposed method is environmentally benign, fast, simple and inexpensive. The combination of MSPE by the as-prepared nano adsorbent with F AAS offers relatively high sensitivity. The LODs of $\mathrm{Pb}\left(2.86 \mu \mathrm{g} \mathrm{\textrm {L } ^ { - 1 } )}\right.$ and $\mathrm{Cu}$ ( $3 \mu \mathrm{g} \mathrm{L}^{-1}$ ) were better than those obtained by F AAS without MSPE. ${ }^{22,23}$ Trace and ultra-trace $\mathrm{Pb} / \mathrm{Cu}$ in several kinds of tobacco samples could be determined with good repeatability and spiked recoveries.

Table 5. The figures of merit of the proposed method $(n=6)$

\begin{tabular}{lccccccc}
\hline Analyte & Calibration equation & $\mathrm{LR}^{\mathrm{a}} /(\mu \mathrm{g} \mathrm{L}-1)$ & $\mathrm{RSD}^{\mathrm{b}} / \%$ & $\mathrm{r}$ & $\mathrm{LOD}^{\mathrm{c}} /(\mu \mathrm{g} \mathrm{L}-1)$ & $\mathrm{LOQ}^{\mathrm{d}} /\left(\mu \mathrm{g} \mathrm{L}^{-1}\right)$ & $\mathrm{EF}^{\mathrm{e}}$ \\
\hline $\mathrm{Pb}$ & $\mathrm{A}=0.005063 \mathrm{C}-0.0006$ & $5-800$ & 5.9 & 0.998 & 0.5 & 1.7 & 52 \\
$\mathrm{Cu}$ & $\mathrm{A}=0.005286 \mathrm{C}+0.0027$ & $2-400$ & 4.5 & 0.999 & 0.2 & 0.7 & 45 \\
\hline
\end{tabular}

${ }^{\mathrm{a}} \mathrm{LR}$ : linear range; ${ }^{\mathrm{b} R S D}$ : relative standard deviation; ${ }^{\mathrm{c}} \mathrm{LOD}$ : limit of detection; ${ }^{\mathrm{d}} \mathrm{LOQ}$ : limit of quantification; ${ }^{\mathrm{e}} \mathrm{EF}$ : enrichment factor. 
Table 6. Analytical results for determination of $\mathrm{Pb}$ and $\mathrm{Cu}$ in different tobacco samples $(\mathrm{n}=6)$

\begin{tabular}{|c|c|c|c|c|c|c|c|}
\hline \multirow{2}{*}{ Sample } & \multirow{2}{*}{ Added / $\left(\mu \mathrm{g} \mathrm{kg}^{-1}\right)$} & \multicolumn{2}{|c|}{ Found / $\left(\mu \mathrm{g} \mathrm{kg}^{-1}\right)$} & \multicolumn{2}{|c|}{$\mathrm{RSD}^{\mathrm{a}} / \%$} & \multicolumn{2}{|c|}{ Recovery / \% } \\
\hline & & $\mathrm{Pb}$ & $\mathrm{Cu}$ & $\mathrm{Pb}$ & $\mathrm{Cu}$ & $\mathrm{Pb}$ & $\mathrm{Cu}$ \\
\hline \multirow{4}{*}{1} & 0 & - & 12.8 & 2.3 & 1.9 & - & - \\
\hline & 50 & $44.6 \pm 0.2$ & $57.7 \pm 0.2$ & 3.9 & 2.7 & 89.2 & 89.8 \\
\hline & 100 & $91.8 \pm 0.5$ & $113.5 \pm 0.5$ & 4.1 & 3.3 & 91.8 & 100.7 \\
\hline & 200 & $191.5 \pm 1.0$ & $207.4 \pm 1.0$ & 2.8 & 3.2 & 95.7 & 97.3 \\
\hline \multirow{4}{*}{2} & 0 & - & 9.6 & 3.7 & 2.1 & - & - \\
\hline & 50 & $45.7 \pm 0.2$ & $56.5 \pm 0.2$ & 5.1 & 2.9 & 91.4 & 93.8 \\
\hline & 100 & $92.2 \pm 0.5$ & $108.5 \pm 0.5$ & 1.9 & 3.8 & 92.2 & 98.9 \\
\hline & 200 & $189.3 \pm 1.0$ & $204.8 \pm 1.0$ & 2.2 & 2.5 & 94.6 & 97.6 \\
\hline \multirow{4}{*}{3} & 0 & - & 20.3 & 3.7 & 2.6 & - & - \\
\hline & 50 & $46.6 \pm 0.2$ & $67.1 \pm 0.2$ & 2.1 & 3.7 & 93.2 & 93.6 \\
\hline & 100 & $94.7 \pm 0.5$ & $115.4 \pm 0.5$ & 1.7 & 3.1 & 94.7 & 95.1 \\
\hline & 200 & $193.0 \pm 1.0$ & $211.9 \pm 1.0$ & 4.2 & 1.8 & 96.5 & 95.8 \\
\hline
\end{tabular}

aRelative standard deviation, data were calculated based on 6 times experiments.

Table 7. Determination of $\mathrm{Pb}$ and $\mathrm{Cu}$ in the certified reference sample with magnetic solid-phase extraction $(\mathrm{n}=3 ; 95 \%$ confidence level)

\begin{tabular}{lccc}
\hline \multirow{2}{*}{ Element } & \multicolumn{2}{c}{ Concentration $\pm \mathrm{SD} /\left(\mu \mathrm{g} \mathrm{L}^{-1}\right)$} & \multirow{2}{*}{ Recovery / \% } \\
\cline { 2 - 3 } & Certified value $^{\mathrm{a}}$ & Found $^{\mathrm{b}}$ & \\
\hline $\mathrm{Pb}$ & $30.0 \pm 2.0$ & $29.0 \pm 2.0$ & 96.6 \\
$\mathrm{Cu}$ & $100.0 \pm 3.0$ & $101.8 \pm 3.0$ & 101.8 \\
\hline
\end{tabular}

${ }^{\mathrm{a} C e r t i f i e d ~ v a l u e ~ a s ~ r e p o r t e d ~ i n ~ c e r t i f i c a t e ; ~}{ }^{\mathrm{b}}$ measured value using the proposed method. SD: standard deviation.

\section{Acknowledgments}

This work was supported by the Faculty of Life Science and Technology, Kunming University of Science and Technology.

\section{References}

1. Hernberg, S.; Am. J. Ind. Med. 2000, 38, 244.

2. Needleman, H.; Annu. Rev. Med. 2004, 55, 209.

3. Tian, Y.; Liu, H.; Wang, Q.; Zhou, J.; J. Environ. Sci. 2014, 26, 1681.

4. Kopittke, P. M.; Asher, C. J.; Blamey, F. P.; Menzies, N. W.; Sci. Total Environ. 2009, 407, 4616.

5. Tian, Y. F.; Hou, H. W.; Zhu, F. P.; Wang, A.; Liu, Y.; Hu, Q. Y.; Biol. Trace Elem. Res. 2014, 158, 9.

6. Inam, R.; Aydin, H.; Anal. Sci. 2006, 12, 911.

7. Qi, B.; Aldrich, C.; Bioresour. Technol. 2008, 99, 5595.

8. Landsberger, S.; Wu, D.; Sci. Total Environ. 1995, 173, 323.

9. Galazynsidorczuk, M.; Brzóska, M. M.; Moniuszkojakoniuk, J.; Environ. Monit. Assess. 2008, 137, 481.
10. de Alcântara, I. L.; Roldan, P. S.; Margionte, M. A. L.; Castro, G. R.; Padilha, C. C. F.; Florentino, A. O.; Padilha, P. M.; J. Braz. Chem. Soc. 2004, 15, 366.

11. Liu, Y.; Said, R.; Abdel-Rehim, M.; J. Chromatogr. B 2017, 1043, 33

12. Sabin, G. P.; Prestes, O. D.; Adaime, M. B.; Zanella, R.; J. Braz. Chem. Soc. 2009, 20, 918.

13. Babazadeh, M.; Hosseinzadehkhanmiri, R.; Abolhasani, J.; Ghorbanikalhor, E.; Hassanpour, A.; RSC Adv. 2015, 5, 19884.

14. Zhou, Q.; Lei, M.; Wu, Y.; Yuan, Y.; J. Chromatogr. A 2017, $1487,22$.

15. Mashhadizadeh, M. H.; Amoli-Diva, M.; Shapouri, M. R.; Afruzi, H.; Food Chem. 2014, 151, 300.

16. Tombácz, E.; Turcu, R.; Socoliuc, V.; Vékás, L; Biochem. Biophys. Res. Commun. 2015, 468, 442.

17. Asgharinezhad, A. A.; Mollazadeh, N.; Ebrahimzadeh, H.; Mirbabaei, F.; Shekari, N.; J. Chromatogr. A 2014, 1338, 1.

18. Ju, S.; Liu, M.; Yang, Y.; Anal. Lett. 2016, 49, 511.

19. Alveroğlu, E.; Sözeri, H.; Baykal, A.; Kurtan, U.; Senel, M.; J. Mol. Struct. 2013, 1037, 361.

20. Tinel, L.; Rossignol, S.; Bianco, A.; Passananti, M.; Perrier, S.; Wang, X.; Brigante, M.; Donaldson, D. J.; George, C.; Environ. Sci. Technol. 2016, 50, 11041.

21. Wang, Y.; Chen, H. H.; Tang, J.; Ye, G. Q.; Ge, H. L.; Hu, X. Y.; Food Chem. 2015, 181, 191.

22. Manzoori, J. L.; Bavili-Tabrizi, A.; Anal. Chim. Acta 2002, 470, 215.

23. Farajzadeh, M. A.; Bahram, M.; Mehr, B. G.; Jönsson, J. Å.; Talanta 2008, 75, 832 .

Submitted: February 21, 2017 Published online: June 27, 2017 